Vol. 2, No. 2, 2020

Review Article

\title{
Understanding Change: A Critical Review of Literature
}

\author{
Ahmed Shaikh \\ University of Manitoba, Canada \\ ahmesshaikhnawaz@gmail.com \\ *Correspondence: ahmesshaikhnawaz@gmail.com
}

\begin{abstract}
Received: 29th $N o v e m b e r ~ 2019 ;$ Accepted: $15^{\text {th }}$ March 2020; Published: $1^{\text {st }}$ May 2020
\end{abstract}
Abstract: The current paper has attempted to shed light on the concept of change and the prominent models that can be of value for managerial authorities to bring transformation in their business. the paper sheds light on change which is refers to the continuous modifications that an organisation or individuals make to deal with adjustments in any matter. The paper highlights that although there are no static models of change yet still, some prominent perspectives and frameworks can be considered for top management and decision making bodies to make sense of the concept of change and work on developing policies and practices to ensure they remain competitive. The article discusses the idea forwarded by Lewin for change which catered to three stages at the first place. Following to this, the article discusses Burke and Litwin model of change that has been widely considered for business sectors for change management. Towards the end, the article discusses the ADKAR model of change. Taken together, the article provides crucial information for change enthusiasts to get firsthand information to start learning about how organizations can bring about objective changes.

Keywords: Change; Change management; Change models; Competitiveness; Review

\section{Introduction}

As it is mentioned, only thins that is a constant is change. As the competition grows and markets shrink due to tougher economic challenges, decision and policy makers require to understand the importance of constantly evolving to remain competitive. This is also essential for them to retain their employees as well as customers. Sadly, what we learn from the organizational scientists that not much attention is being paid to this element particularly when it requires altering major company rules and practices. Notably, scholars have also indicated reluctance towards change because of lack of knowledge and understanding thus putting managers and key executives in confusion about that the change is and how to bring about transformation in any business activity or process. The current paper aims to address this issue through offering an 'easy to understand' overview of change and the popular models of change that could be of interest to organizational entities aspiring to evolve and transform.

\section{Literature Review}

\subsection{Defining Change}

The term change refers to the continuous modifications that an organisation or individuals make to deal with adjustments in any matter (Waraich and Bhardwaj, 2007). In the continuously demanding environment for change as a result of globalization, technology evaluation or higher customer expectation, management of change is crucial for organization continuity and development. Therefore, change is a 
process, not an event. National Learning Consortium has defined change management from three integrated perspectives including process as "the application of the set of tools, processes, skills and principles for managing the people side of change to achieve the required outcomes of a change project or initiative" (Kliewe, Davey and Baaken, 2013). An organization is a group of individuals and the individual behaviors is a result of the system of forces that surrounds the individuals in different context (Shimoni, 2017). There is no standard change model that can fit all organizations; however, some may be more effective than others and some maybe tuned to fit specific organizational need.

\subsection{Models of Change}

One of the first initiated change models is by Kurt Lewin (1947). Lewin developed a social change model based on three fundamental steps to implement a planned change. Lewin explains that the change is like ice cubes and goes in a process of three steps as follows: (a) unfreezing (b) moving (c) refreezing.

The first stage is unfreezing, which is creating people's readiness for change by changing their behaviors towards the change. Unfreezing includes raising people awareness about the current situation and the planned change, giving incentives towards engaging people with the planned change (Bakari, Hunjra and Niazi, 2017).The first stage of Lewin's model is the most difficult stage to start the change and this stage needs time to be completed and nurtured to overcome change resistance and letting go of the old behavior which does not support the change. The second stage is moving or changing a set of behavior/s to another behavior/s that is more supportive and acceptable for the planned change (Burnes *, 2004). It is the stage of commitment for the planned change as the researchers Bakari, Hunjra and Niazi suggest (2017). The third stage of Lewin's model is refreezing to bring the situation to steadiness and to make the change permanent and get support to sustain the change and maintain it as planed in stage one.

Lewin's model is considered the father for other models. It is simple to implement and has only three defined short steps. However, Lewin ignored the fact that change is continuous as life continues and may happen in any stage of the three stages causing a disruption of the change process and being in status quo.is unrealistic and may cause behavioral shock when the change starts any time (Burnes, Hughes and By, 2016).

Armenakis, Brown and Mehta, (2011) recommend two change management models in their qualitative research paper for the assessment and transformation of organization culture, and both models are based on Kurt Lewin (1947) model. The first model creates readiness for change, which is a conscious organizational change with a structured plan and designate trained team called 'change agents', and it aims to convey the required change message. The second model is the adoption and institutionalization of change, which is used to complement the first model for the implementation and farther guidance on embrace and reinforce the change message conveyed by the first model in case part of the change recipient rejected the change massage in the initial stages.

A revolutionary model was designed by Burke and Litwin (1992), who suggest a model called causal model of organizational performance and change- or Burke and Litwin model. This model is a comprehensive and complex model, which is well-structured as a system to include twelve change variables that impact people in the organization. The model variables are represented in as boxes linked with arrows as illustrated in below in Figure 1: 


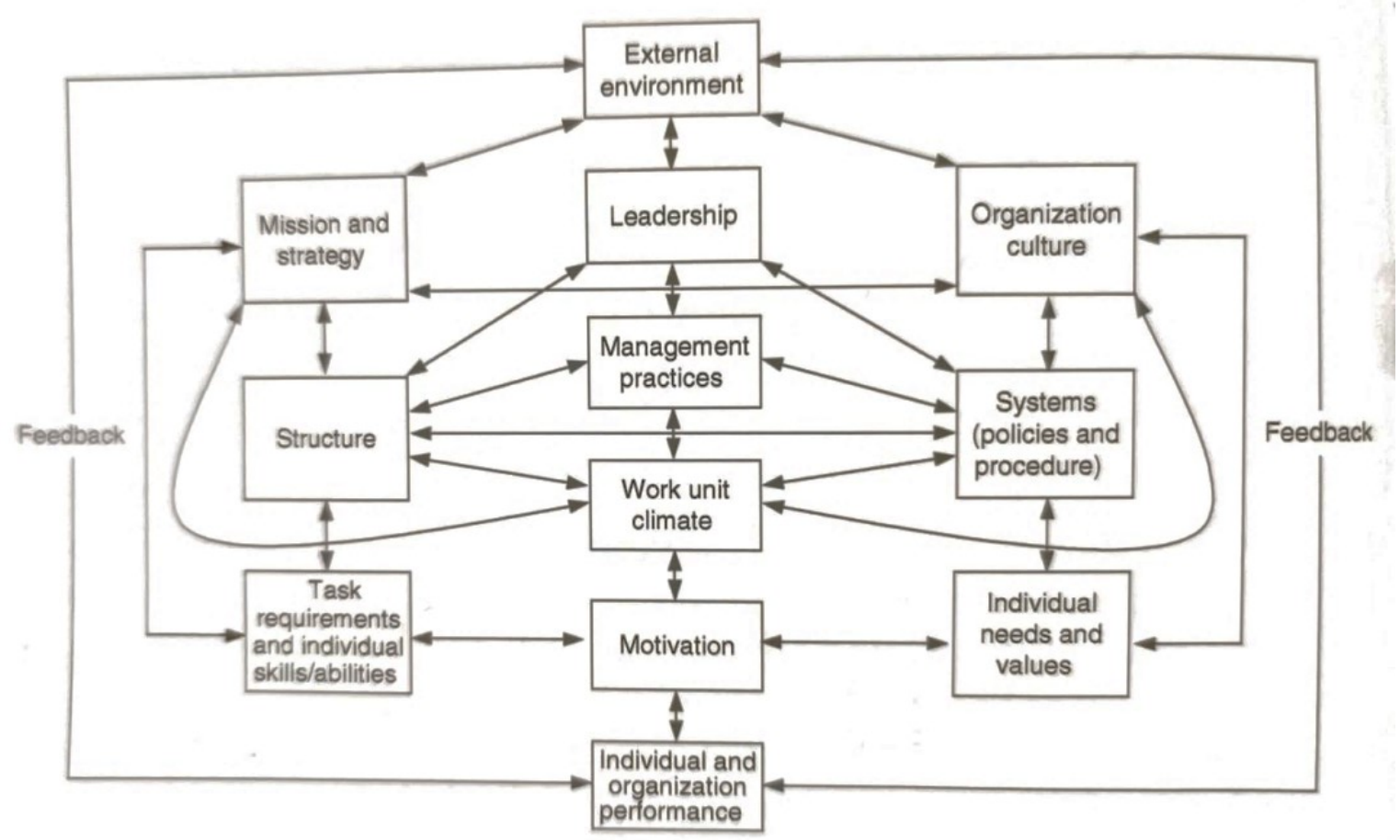

Figure 1: Burke \& Litwin Model of Organizational Performance and Change

Burke and Litwin's model is based on General System Theory (GST). The GST and includes input, output, process, and feedback, where the feedback element represents the system control element (Von Bertalanffy, 1972). Burke and Litwin assert that both the input and output elements affect each other. This relationship is illustrated in Figure 1 in arrows going from the external environment box to the individual and organizational performance box and that relationship is also valid in the opposite direction. The most important change variables as Burke and Litwin explain is the external environment variable (i.e. change in government rules and regulations or natural climate change), as it forces the organization and individual to change accordingly. Therefore, it considered as an Input element (Awasthy, Vijayalakshmi and Gupta, 2013). On the other hand, the output element is represented by the individual and organizational performance variable such as products and services (Burke and Litwin, 1992). The process element as in the GST is embodied in Burke and Litwin model in two different dimensions: transformational and transactional. For the success of the model implementation it is important to distinguish between the two dimensions and understand the relationship that link all variables in Burke and Litwin's model system.

The transformational dimension is a group of a long-term change variables, which have a strategic impact on the individual and organization performance. These variables are represented in Burke and Litwin model in the upper boxes in Figure 1, and include mission and strategy, leadership, and organizational culture. This means that the transformational dimension change as a result of external environment force and accordingly this will lead to changes in employee's behavior pattern. The second dimension is the transactional short-term change variables, which have an operational and administrative impact on the organization. The transactional variables are represented by the lower boxes in Figure 1, and include motivation, structure, systems (policies and procedures), management practices, work unit climate, individual needs and values, and individual task and skills (Burke and Litwin, 1992).

Another model change model which is well known for its simplicity is ADKAR model of change, developed by Jeffery Hiatt in 2006. ADKAR suggests that the process of change management is more personal and individualistic, which focuses on how to enable the change through people as individual. The model consist of five steps refers to each letter in the model name ADKAR, which is Awareness of the 
change in need, the Desire to support and to participate in the change, the Knowledge on how the change should take place, the Ability to implement the change it self and finally the Reinforcement of the change to maintain its sustainability (Figure 2), (Hiatt, 2006). Individual commitment and engagement are the change process is fundamental to achieve a successful change process in the organization in other word achieving the change is the goal of people and organization in ADKAR model of change. (Kliewe, Davey and Baaken, 2013). Moreover, the founder of ADKAR model insists that the model requires high level of communication in all the stages using written, verbal, training, coaching and knowledge sharing to maintain total engagement in the process (Hiatt, 2006).

Accordingly, organization planning for change or facing changes may combine more than one change model according to the purposes of change.

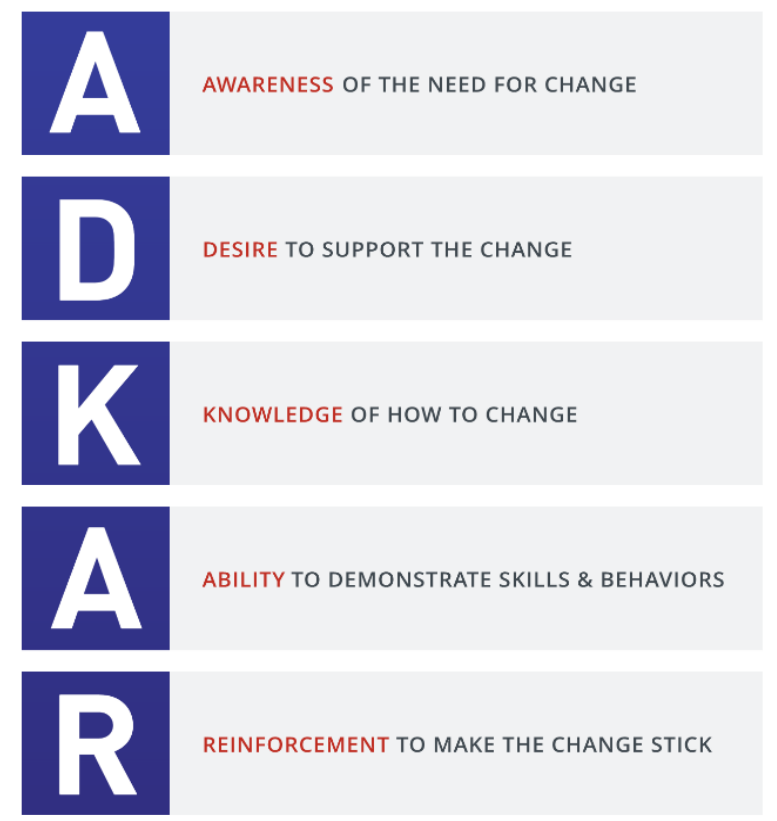

Figure 2: ADKAR Model of Change

\section{Conclusion}

The paper has attempted to outline the concept of change and the different change management models for managers to understand the concept and its process. The article has endeavored to serve as a simple yet insightful knowledge on change and how they can potentially drive in their organizations to survive and sustain the tough market situations.

\section{References}

Gjerløv-Juel, P., \& Guenther, C. (2019). Early employment expansion and long-run survival: examining employee turnover as a context factor. Journal of Business Venturing, 34(1), 80-102.

Armenakis, A., Brown, S., \& Mehta, A. (2011). Organizational culture: Assessment and transformation. Journal of Change Management, 11(3), 305-328.

Awasthy, R., Vijayalakshmi, C., \& Gupta, R. K. (2013). Corporate transformation or cosmetic makeover? Case of a public sector bank in India. Indian Journal of Industrial Relations, 67-81.

Bakari, H., Hunjra, A. I., \& Niazi, G. S. K. (2017). How does authentic leadership influence planned organizational change? The role of employees' perceptions: Integration of theory of planned behavior and Lewin's three step model. Journal of Change Management, 17(2), 155-187.

Burke, W. W., \& Litwin, G. H. (1992). A causal model of organizational performance and change. Journal of management, 18(3), 523-545. 
Burnes, B., Hughes, M., \& By, R. T. (2018). Reimagining organisational change leadership. Leadership, 14(2), 141-158.

Hiatt, J. (2006). ADKAR: a model for change in business, government, and our community. Prosci.

Kliewe, T., Davey, T., \& Baaken, T. (2013). Creating a sustainable innovation environment within large enterprises: a case study on a professional services firm. Journal of Innovation Management, 1(1), 55-84.

Lewin, K. (1947). Group decision and social change. Readings in social psychology, 3(1), 197-211.

Shimoni, B. (2017). What is resistance to change? A habitus-oriented approach. Academy of Management Perspectives, 31(4), 257-270.

Von Bertalanffy, L. (1972). The history and status of general systems theory. Academy of management journal, 15(4), 407426.

Waraich, S. B., \& Bhardwaj, G. (2007). The World of Corporate Changes, Transitions and HR Competencies. Indian Journal of Industrial Relations, 43(2), 269-290.

(C) 2020 by the author(s). Published by Annals of Contemporary Developments in Management 